\title{
A combined supply chain optimisation model for the installation phase of offshore wind projects
}

\author{
Chandra A. Irawan ${ }^{1, *}$, Negar Akbari ${ }^{2}$, Dylan F. Jones ${ }^{2}$, David Menachof ${ }^{3}$ \\ ${ }^{1}$ Nottingham University Business School China, University of Nottingham Ningbo China, Ningbo, China \\ ${ }^{2}$ Centre for Operational Research and Logistics, Department of Mathematics, University of Portsmouth, \\ Lion Gate Building, Lion Terrace, Portsmouth, PO1 3HF, UK \\ ${ }^{3}$ College of Business, Florida Atlantic University, Boca Raton, Florida USA
}

\begin{abstract}
This paper proposes a combined model for port selection and supply chain optimisation for the installation phase of an offshore wind farm. Two strategic models are proposed where the first model, based on Analytical Hierarchy Process (AHP), aims to select the most suitable installation port. The second model is developed using Integer Linear Programming (ILP) in order to determine the optimal transportation schedule of the components from suppliers to the chosen installation port. The proposed models are evaluated for the West Gabbard (UK) offshore wind farm located in southern part of the North Sea. According to the computational results, the AHP model chooses port of Oostende, Belgium as the most suitable installation port for this offshore wind farm whereas the proposed supply chain model shows that the total transportation cost makes up $9 \%$ of total supply chain cost.
\end{abstract}

Key words: Supply chain optimisation, port selection, logistics, renewable energy, offshore wind farm

\section{Introduction}

The production of energy from offshore wind sources is gaining momentum in numerous countries including Northern European countries, China, South Korea and the United States. Offshore wind provides countries with a clean and renewable source of energy and outperforms onshore wind energy in terms of the capacity factor and power output while also avoiding some of the barriers associated with onshore wind turbines such as the visual problems, noise and land occupation (Snyder and Kaiser, 2009). Currently, Europe is the world leader in terms of installed capacity with over $12 \mathrm{GW}$ of operational offshore wind farms spread across 11 countries (Wind Europe, 2016). China has ambitious plans of developing $30 \mathrm{GW}$ by 2020,

\footnotetext{
*Corresponding Author: chandra.irawan@ nottingham.edu.cn
} 
South Korea plans for 7.5 GW by 2030 (Poulsen and Lema, 2017) and the US has developed its first utility scale $30 \mathrm{MW}$ project off the state of Rhode Island and plans for further commercial developments (Archer et al. 2017).

However, the potentially high cost of an offshore wind farm which arises from the complex construction and development of the project is amongst the concerns for further development of the industry and governments currently supporting the industry require cost competitiveness with other non-fossil based energy sources within the next decade (DECC, 2013). Offshore wind energy development is dependent on a complex logistical and shipping process that is a result of the extremely large size of the components and a challenging offshore installation process (Poulsen and Lema, 2017). It is envisioned that optimisation within the supply chain and logistics of the offshore wind projects can have a positive effect on bringing down the cost of energy. The construction of the wind farm is composed of (i) inland and (ii) offshore activities. The former involves the production and transportation of the wind turbine components to a suitable installation port where they are stored and assembled, and the latter involves the offshore installation of the components.

In this paper, we investigate the strategic problem related to the transportation of the components from the suppliers to the offshore wind farms that is composed of two parts: Firstly, the decision maker selects the most suitable installation port based on different logistics criteria using a multi-criteria decision making (MCDM) method. Thereafter, the supply chain network is developed which includes the transportation, inventory and production of the components sent from the suppliers to the chosen installation port.

The topic of port selection has been widely studied for container port selection as evidenced in the work of Ugboma et al., (2006), Chou (2010) and Zavadskas (2015). However, with the emergence of marine renewable energies such as offshore wind, wave and tidal energy, ports have taken a different role and act as platforms in which offshore activities including assembly and storage of components can take place. Two recent studies deal with port developments in the offshore wind sector. Irawan et al. (2017) have developed a mathematical optimisation model for finding the optimal layout configuration of a port for the installation phase of the offshore wind farm. Their model considers different compartments within the port and suggests an optimal layout that minimizes the total transportation cost of moving the components between the different compartments. Akbari et al. (2016 \& 2017) analyse the port requirements for the offshore wind sector and propose the Analytical Hierarchy Process (AHP) for port selection. However, their model is not implemented within the broader context of the 
offshore wind supply chain. In this research, the proposed AHP method by Akbari et al. (2016 $\&$ 2017) is used and extended to an ILP approach for developing the supply chain network for the installation phase of offshore wind farms.

The AHP has been used in conjunction with mathematical optimisation methods in the literature. In the study by Galvez et al. (2015), ILP is used for optimising a logistics network for waste treatment by means of anaerobic co-digestion. After determining the optimal projection for each scenario, the AHP is used to select the most suitable scenario taking into account different criteria from the decision makers' point of view. In a fuzzy scenario, Ozgen and Gulsun (2014) propose a combine a two phase possibilistic linear programming model and fuzzy AHP that optimises two objective functions of minimum cost and, maximum qualitative factors benefit in a four-stage (suppliers, plants, distribution centres, customers) supply chain network in the presence of vagueness.

Given the literature in the offshore wind sector, a gap was recognized in the available supply chain models for the installation phase. This study fills this void with the following contributions:

- The development of a combined model for port selection and supply chain optimisation in the offshore wind industry

- The usage of the combined model on an existing UK wind farm and the resulting discussion of the results.

The remainder of this paper is organised as follows. In Section 2, a literature review on MCDM is presented, followed by supply chain optimisation methods in the renewable energy sector. In Section 3, the port selection model and the supply chain optimisation formulations are discussed in detail. In Section 4, the case application related to the supply chain optimisation of an offshore wind farm off the coast of the United Kingdom is presented. Conclusions are and future research directions are presented in Section 5.

\section{Literature Review}

This section presents a literature review on the application of multi-criteria decision making (MCDM) to port selection followed by supply chain optimisation methods in the renewable energy sector. 


\subsection{Multi Criteria Decision Making (MCDM)}

For solving multi-criteria problems referring to making preference decisions (i.e. evaluation, selection, prioritization), over a discrete set of available alternatives, different MCDM methods have been developed (Hwang and Yoon, 1981). These methods are mainly based on two different concepts of a) multi-attribute utility theory (MAUT), which has a compensatory nature and consists of aggregating the criteria into a function which has to be maximised, and b) outranking methods; which allow for incomparability between alternatives and therefore have a non-compensatory nature. Methods such as the Analytical Hierarchy Process (AHP), Analytical Network Process (ANP), TOPSIS, and Complex Proportional Assessment (COPRAS) are based on the MAUT concept, while methods such as ELECTRE and PROMOTHEE are based on the outranking concept (Mulliner et al. 2016).

The variety of MCDMs makes the selection of a suitable method an important task for researchers and practitioners. A number of studies have made a comparative study between the results of different techniques in order to assist the justification of one method over another. Zanakis et al. (1998) used simulation to compare five different MCDMs including, TOPSIS, ELECTRE, SAW, MEW and four variants of AHP. Zanakis et al. (1998) concluded that in general, all variants of AHP behaved similarly and closer to WSM compared to other methods. TOPSIS behaved closer to AHP and differently from ELECTRE and WPM (except for problems with few criteria), ELECTRE was the least similar to SAW (except for best matching the top ranked alternative) followed by MEW.

In another study by Mulliner et al. (2016) five methods including WSM, MEW, revised AHP, TOPSIS and COPRAS were compared for solving a sustainable housing affordability problem. The COPRAS method was suggested for their studied problem and TOPSIS, WSM and WPM were proposed as good candidates in cases where there was a higher level of uncertainty with regard to the importance of the criteria.

For the first part of this study, the AHP has been proposed for port suitability assessment due to its practicality, ability to provide a framework for group participation in decision-making and ease of use for stakeholders (Wedley, 1990). Since the experts and users of the proposed port selection model are industry practitioners in the offshore wind sector, one of the main criteria in choosing the method was its ease of use by the users and experts. Additionally, the AHP methodology provides a complete ranking of the alternatives, and it is able to handle both quantitative and qualitative criteria. While in outranking methods such as ELECTRE, the 
process and outcome can be difficult to explain in layperson's terms (Velasquez and Hester, 2013), the AHP's results are easily understood and make intuitive sense to the users (Wedley, 1990). Furthermore, whilst in some MCDM methods such as PROMETHEE, a clear method by which to assign weights in not provided, the AHP clearly addresses the process and suggests the consistency ratio (CR) index for determining the consistency of expert judgements (Velasquez and Hester, 2013). The AHP balances the interactions among decision criteria, and synthesizes the information into a vector of preferences among the vector of alternatives. Hobbs (1986) suggests that the AHP helps the decision makers to a) articulate and model the preferences, b) structure the decision process, c) aggregate the alternative evaluations, and d) make recommendations.

\subsection{Applications of MCDM in the offshore energy sector}

In the offshore wind sector, Lozano-Miguez et al. (2011) used the TOPSIS method for the benchmarking of candidate support structures for offshore wind turbines considering engineering, economic and environmental attributes. In a study by Rabbani et al. (2014) the performance of oil producing companies were evaluated using ANP, for formulating the interdependency among criteria, and CORPAS, for evaluating the alternatives. Fetanat and Khosraninejad (2015) used a combined fuzzy multi-criteria decision approach for offshore wind site selection in southwest of Iran. Six criteria were used including the depth and height, environmental issues, proximity to facilities, economic aspects, culture and technical resources and levels. Yunna et al. (2016), used MCDM to study a problem related to offshore wind farm site selection in China. An ELECTRE 3 method was used in a fuzzy environment. Six groups of criteria were selected including wind resources, construction and maintenance condition, supporting conditions onshore, environmental impacts, economic, and society benefits. Vasileiou et al. (2017) used a GIS based MCDM for site selection of hybrid offshore wind and wave systems. In the first stage of their study the authors used the GIS to in order to identify suitable areas for the development of hybrid wind and wave systems in Greece. In the second stage of the study, the AHP method was used to rank the eligible marine areas that didn't satisfy the exclusion criteria. 


\subsection{Supply Chain Optimisation Model}

In the literature, several papers have investigated the supply chain in the offshore wind industry. He and Chen (2009) provided a review of the status and the problems of wind turbine generator system manufacturing and supply chain in China. Wee et al. (2012) examined renewable energy sources including wind energy from a supply chain perspective and provided an investigation of renewable energies focusing on four main components namely renewable energy supply chain, renewable energy performance, and barriers and strategies to its development. Heffron and McCauley (2014) discussed the nexus of energy justice, supply and security where an example of the wind energy sector in Denmark was used which demonstrated how the application and promotion of energy justice can enable the growth of an industry supply chain. Zhao et al. (2014) used the general industry chain theory to establish a wind power industry chain model and examined the operation mechanisms of the industry. They developed three models namely the supply chain, the technology chain and the value chain models which represented the supply-demand relationship, technology transfer and value creation of wind power related industries respectively. Yuan et al. (2014) presented a supply chain framework and comprehensive review on the wind power industry in China. They identified key stake holders along with their concerns in the supply chain. They also summarized the evolution of related policies in both upstream and downstream aspects of the supply chain. Wüstemeyer et al. (2015) presented a survey-based analysis of investment decisions and structural shifts related to onshore and offshore wind power supply chains. They concluded that the wind power industry had experienced a decoupling process of the offshore supply chain from its onshore counterpart with diverging technological requirements.

The papers cited above deal with supply chain management in a general sense instead of supply chain optimisation. However, there is a dearth of papers in the literature that address supply chain optimisation in an offshore wind farm. Nevertheless, general supply chain optimisation has been widely investigated. Our proposed model developed using ILP can be considered as the multi-product (component/part) and multi-period supply chain network problem where a set of components/parts needs to be transported to plants to be transformed into final products that are delivered to final destinations. Therefore, in this subsection we review some papers dealing with the multi-product supply chain network problem using ILP or Mixed ILP (MILP). A paper by Geoffrion and Graves (1974) can be considered as one of the pioneering works in supply chain network design optimisation where they introduced a MIP model and a solution technique for the multi-commodity distribution problem. 
Cohen \& Lee (1988) proposed the framework of global manufacturing and distribution problems consisting of four sub-models where a nonlinear MIP model was developed to tackle the problem. A MILP model to solve a production and transport planning problem in the chemical industry in a multi-plant, multi-product and multi-period environment was proposed by Mcdonald and Karimi (1997). Wilkinson et al. (1996) proposed an aggregated planning model involving integration of production, inventory, and distribution in multisite facilities. A MILP model was introduced by Barbarosoglu and Ozgur (1999) where the model was solved by a Lagrangian relaxation method. Goetschalckx et al. (2002) presented two mixed integer linear programming models, one for the supply chain design phase and the other for production planning, inventory planning and national supply chain transport planning with seasonal demand. Jang et al. (2002) proposed four modules for supply chain management, namely supply chain design, production and distribution planning, the model management module and the data processing module. Gen and Syarif (2005) developed a MILP model for production and transport planning which was solved by genetic algorithms and fuzzy methods. An integrated transport and production planning model in a multi-site, multi-retailer, multi-product and multi-period environment was proposed by Park (2005) and Eksioglu et al. (2006). A MILP model that incorporates mixes, loads and transport between various sea ports used in the cereal industry was proposed by Bilgen and Ozkarahan (2007) considering a multi-period environment. Romo et al. (2009) applied a MILP model for solving Norwegian natural gas production and transport. Verderame and Floudas (2009) investigated an operational planning model which captures the interactions between production facilities and distribution centres in a multisite production facilities network.

Mula et al. (2010) provided a review of mathematical programming models for supply chain production and transport planning. Tang et al. (2013) investigated supply chain scheduling from the perspective of networked manufacturing considering three objective functions namely time, cost and delay punishment functions. Cárdenas-Barrón and Treviño-Garza (2014) developed a model to obtain an optimal solution to a three echelon multi-product and multiperiod supply chain network. Fahimnia et al. (2015) proposed a practical supply chain optimisation model in the presence of economic and carbon emission objectives. The proposed model was applied to assess the possible economic and environmental trade-offs for various carbon-pricing and fuel-pricing scenarios. Abedi and Zhu (2017) investigated an optimisation model for spawn purchase, fish culturing production process and harvested fish distribution in 
a fish supply chain. Recently, Khalili et al. (2017) proposed a model for integrated production and distribution planning problem in a two-echelon supply chain under risk.

In this paper, we develop a supply chain optimisation model for an offshore wind farm industry where the supply chain problem in this sector is distinct from the models detailed above.

\section{Description of the Models}

In this section, the description of the proposed AHP based port selection model is first presented in subsection 3.1. The result of the port selection model is fed into the supply chain optimisation model, which will be discussed in subsection 3.2.

\subsection{Port selection model}

The port selection model determines the suitability of the ports for hosting the installation phase of an offshore wind farm from a logistics perspective considering three main criteria groups of Port's physical characteristics, Port's connectivity and Port's layout. The criteria that have been used for this study are obtained via literature and industrial report surveys (Tetratech, 2010; Garrad Hassan, 2014; D'Amico, 2012). The developed AHP model is then validated through interviews with different offshore wind stakeholders in the offshore wind farm construction, port design and port management. For determining the weights of the criteria, the pairwise comparison has been used. The weight of each criterion and sub-criterion is derived based on the experts' judgements who provided pairwise comparisons based on Saaty's numerical scale (Saaty 2000). Five experts on the managerial level were selected from different organisations and were given two weeks to respond to the questionnaires. The description of the experts is given below:

- Expert 1 (Senior project manager): Worked in Wind Energy for 7 years including the development of a major port based component manufacturing facility on the East coast of the UK for the last four years.

- Expert 2 (Managing Director): Worked with a renewable energy company writing the bid to secure a Round 3 Development Licence and a formal Development Consent Order (DCO) from The UK Crown Estate. 
- Expert 3 (Managing Director): Developed the strategy for a major British utility company round 3 project and led the selection of an O\&M port on the East coast of the UK for the company's East Coast Assets.

- Expert 4 (Operations manager): Worked on support of the installation phases on various North Sea Wind Farms within the German Sector.

- Expert 5 (General Manager): Worked on the design and development of a port for the Norwegian offshore wind sector.

The methodology for application of the AHP for port selection is given below:

a. Select a set of potential alternatives (ports):

A number of potential ports which have been involved in, or are in the development process of preparing for the offshore wind industry have been selected. All the alternatives possess the minimum necessary requirements for supporting the offshore wind industry.

b. Collect data for each alternative related to the criteria proposed:

The port data is collected based on the attributes developed. The secondary quantitative and qualitative data, using publically available port data is used. The data is normalised as a criterion may have a different unit of measurement as compared to the others.

c. Calculate the final score of each alternative by using the derived criteria weights:

The final score of each port is calculated by summing the product of the normalised data and the weight for each attribute/criterion and the port with the highest overall ranking is suggested as the most suitable port.

The installation port hierarchy (Table 1) is composed of different levels described below:

Level 1: consists of the port's physical characteristics, connectivity and port layout.

Level 2A: consists of the component handling equipment at the port, quay load bearing capacity, port depth, seabed suitability, and quay length.

Level 2B: consists of the port's distance to the wind farm, distance to road networks and distance to key component suppliers.

Level 2C: consists of the availability of storage facility, availability of manufacturing facility, potential for further expansion at the port, and the availability of laydown area at the port.

Level 3A: consists of the availability of Roll on/Roll off (Ro-Ro) vessels, Lift on/Lift off (LoLo) vessels and heavy cranes. 
Level 3B: consists of the open storage area, covered storage area, and load bearing capacity of the storage area.

Level 3C: consists of the laydown area, and laydown area access to quayside.

The final weight of the sub criteria and the consistency index of each level are presented in

Table 1 and 2 respectively.

Table 1: Criteria weights for the installation port

\begin{tabular}{|c|c|c|c|c|c|}
\hline \multirow{2}{*}{$\begin{array}{c}\text { Criteria } \\
\text { Port's physical characteristics }\end{array}$} & \multicolumn{3}{|c|}{ Weight } & \multirow{3}{*}{$\begin{array}{c}\text { Priority Weight }(\%) \\
- \\
10 \%\end{array}$} & \multirow{3}{*}{$\begin{array}{c}\text { Rank } \\
- \\
4\end{array}$} \\
\hline & 0.483 & & & & \\
\hline Seabed suitability & & 0.201 & & & \\
\hline Component handling & & 0.130 & & - & - \\
\hline Lo-Lo capability & & & 0.596 & $4 \%$ & 10 \\
\hline Ro-Ro capability & & & 0.102 & $1 \%$ & 17 \\
\hline Heavy cranes & & & 0.302 & $2 \%$ & 15 \\
\hline Quay length & & 0.145 & & $7 \%$ & 5 \\
\hline Quay load bearing capacity & & 0.287 & & $14 \%$ & 2 \\
\hline Port's depth & & 0.236 & & $11 \%$ & 3 \\
\hline Port's Connectivity & 0.275 & & & - & - \\
\hline Distance to offshore site & & 0.706 & & $19 \%$ & 1 \\
\hline Distance to key component supplier & & 0.186 & & $5 \%$ & 8 \\
\hline Distance to road & & 0.109 & & $3 \%$ & 11 \\
\hline Port's layout & 0.242 & & & - & - \\
\hline Potential for expansion & & 0.257 & & $6 \%$ & 6 \\
\hline Component laydown area availability & & 0.334 & & - & - \\
\hline Component laydown area & & & 0.654 & $5 \%$ & 7 \\
\hline Laydown area access to quay side & & & 0.346 & $3 \%$ & 13 \\
\hline Storage & & 0.289 & & - & - \\
\hline Storage load bearing capacity & & & 0.599 & $4 \%$ & 9 \\
\hline Open storage area & & & 0.300 & $2 \%$ & 14 \\
\hline Covered storage area & & & 0.101 & $1 \%$ & 16 \\
\hline Component fabrication facility & & 0.121 & & $3 \%$ & 12 \\
\hline
\end{tabular}

Table 2: Consistency ratio of each criteria level for the installation port

\section{Level}

\section{Consistency Ratio}




\begin{tabular}{|c|c|}
\hline 1 & 0.163 \\
\hline 2A & 0.017 \\
\hline 2B & 0.020 \\
\hline 2C & 0.021 \\
\hline 3A & 0.077 \\
\hline 3B & 0.060 \\
\hline 3C & 0.000 \\
\hline Average consistency of the matrices & 0.048 \\
\hline
\end{tabular}

\subsection{Supply chain optimisation model}

In the installation phase of an offshore wind farm, supply chain optimisation involves making decisions for planning and design of production, storage locations and transportation of supply chains, which are vital for retaining the competitive edge of companies. Such optimisation models are usually very hard to solve as the problem is often very complex due to the large number of entities of the supply chain such as the number of suppliers, manufacturers/plants and warehouses (ports). Moreover, there are complex interactions among these entities such as inventory policies, modes of transport and relocation of warehouses. Mathematical optimisation techniques have been used to solve such problems. In this section, a supply chain optimisation model for an offshore wind farm is studied focusing on transport to an installation port. The model is developed in order to minimise total supply chain network cost, which includes transportation, inventory, and production costs. A mathematical model using integer linear programming (ILP) is proposed to address the problem.

Figure 1 shows the proposed supply chain network of an offshore wind farm in this study. In the installation phase of an offshore wind farm, the supply chain network is triggered by the installation schedule of the wind turbines. From the schedule, the amount (demand) of main components required by an installation port per period (day) is determined. The installation port is selected by the model given in Section 3.1. The proposed supply chain optimisation model aims to determine the optimal components/parts movement from suppliers to an installation port in order to minimise the total cost including inventory, production and transportation costs. In addition, the model is developed in order to meet the demand of installation ports on the main components for installation process. In the model, the main 
components comprise foundation, transition piece, tower, nacelle, and blades whereas parts are the objects required to assemble main components. These main components will be transported to and stored in the installation ports before they are loaded into the installation vessels.

Figure 1 reveals that suppliers may produce the parts and components. The components/parts can be delivered via inland transportation (truck), sea transportation (vessel), or both truck/train and vessel. If the parts and components need to be shipped by a vessel, they will be transported to the nearest and suitable port first (secondary port). The minimum and maximum amount of parts or components that can be transported by a vessel in one trip is taken into account in the proposed model. If the suppliers or plants are located at the port, the components are usually transported by vessel, otherwise they are transferred by truck/train or both truck/train and vessel. In the proposed model, the transportation mode used for each flow and each component/part is optimised based on its transportation cost and time. The model also considers the inventory cost to store the main components/parts in suppliers, secondary ports, plants and installation ports. In many cases, suppliers, plants and ports have limited storage capacity for storing components and parts.

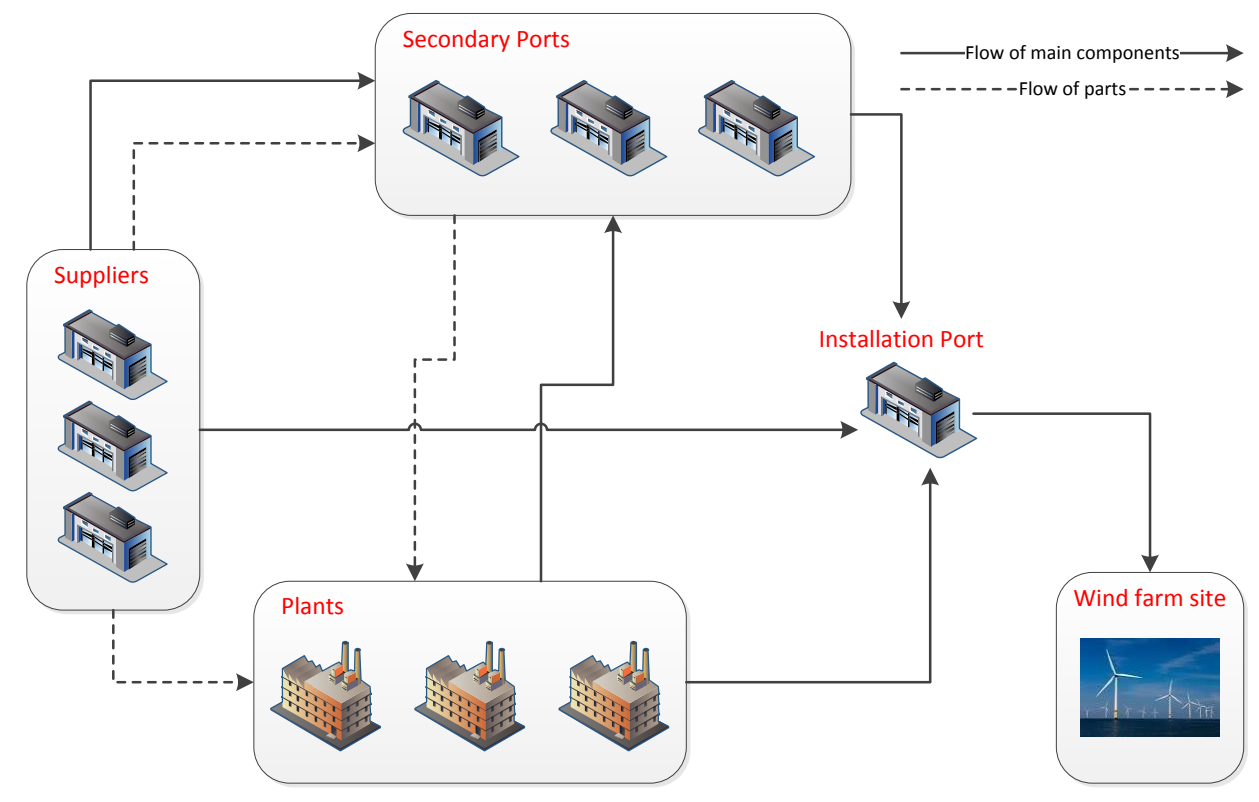

Figure 1: Supply chain network for an offshore wind farm

The components can be produced by either manufacturers/plants or suppliers. In case that the components are manufactured by plants, parts supplied from suppliers are required for assembling the main components. Parts must arrive at the plants in a certain period that can satisfy the demand of main components. Here, the production cost, time and capacity along with the bill of material for each component are also taken into account in the model. Suppliers 
have a limited capacity in providing parts and main components. In this model, the suppliers have a schedule when parts or main components are available. The following notations are used to describe the sets and parameters of the proposed supply chain optimisation model.

\section{$\underline{\text { Sets }}$}

$F \quad$ set of wind farm sites with $f$ as its index

$P \quad$ set of main components with $p$ as its index

$S \quad$ set of parts with $s$ as its index

$R \quad$ set of suppliers with $r$ as its index

$O \quad$ set of plants/manufacturers with $o$ as its index

$K \quad$ set of ports (secondary and installation ports) with $k$ as its index

$W \quad$ set of inland transportation modes with $w$ as its index

$V \quad$ set of vessels with $v$ as its index

$T \quad$ set of periods in the planning horizon with $t$ as its index

\section{Parameters}

Supplier

${ }^{S R} C_{S r} \quad$ the unit cost of part $s$ provided by supplier $r$.

${ }^{P R} C_{p r} \quad$ the unit cost of component $p$ provided by supplier $r$.

${ }^{\text {outSR }} H_{s r} \quad$ the holding cost per period of outbound inventory for part $s$ at supplier $r$.

${ }^{S R} G_{s r t} \quad$ the amount of part $s$ produced by supplier $r$ in period $t$.

${ }^{\text {outPR }} H_{p r t} \quad$ the holding cost per period of outbound inventory for comp. $p$ at supplier $r$.

${ }^{P R} G_{p r t} \quad$ the amount of component $p$ produced by supplier $r$ in period $t$.

\section{$\underline{\text { Plant }}$}

$A_{p o}$

the production cost of product $p$ per unit at plant $o$.

${ }^{i n S O} H_{s o} \quad$ the holding cost per period of inbound inventory for part $s$ at plant $o$.

${ }^{\text {out }} \mathrm{SO}_{\mathrm{po}} \quad$ the holding cost per period of outbound inventory for component $p$ at plant $o$.

${ }^{\text {prod }}$ Cap po the total amount of component $p$ that can be produced by plant $o$ in the planning horizon.

${ }^{\text {invinO }}{ }^{\mathrm{Cap}} \mathrm{O}$ the maximum capacity of the total inbound inventory at plant $o$.

${ }^{\text {invoutO }} \mathrm{Cap}_{\mathrm{O}}$ the maximum capacity of the total outbound inventory at plant $o$.

${ }^{p r o d} T_{p o} \quad$ the amount of periods required to produce component $p$ at plant $o$.

$\underline{\text { Port }}$ 

${ }^{S K} H_{s k} \quad$ the holding cost per period of part $s$ at port $k$.
${ }^{P K} H_{p k} \quad$ the holding cost per period of component $p$ at port $k$.
$D_{p k t} \quad$ the demand of component $p$ for installation in period $t$ at port $k$.
${ }^{i n v K} \mathrm{Cap}_{k} \quad$ the inventory capacity for all parts and components at port $k$.

\section{$\underline{\text { Transportation }}$}

${ }^{t r S R K} C_{\text {srkw }}$ the inland transportation cost of one unit part $s$ from supplier $r$ to port $k$ using transportation mode $w$.

${ }^{\operatorname{trSRO}} C_{\text {srow }}$ the inland transportation cost of one unit part $s$ from supplier $r$ to plant $o$ using transportation mode $w$.

${ }^{t r S K O} C_{\text {skow }}$ the inland transportation cost of one unit part $s$ from port $k$ to plant $o$ using transportation mode $w$.

${ }^{\operatorname{tr} P R K} C_{\text {prkw }}$ the inland transportation cost of one unit component $p$ from supplier $r$ to port $k$ using transportation mode $w$.

${ }^{t r P O K} C_{\text {pokw }}$ the inland transportation cost of one unit component $p$ from plant $o$ to port $k$ using transportation mode $w$.

${ }^{t r S K} C_{s k k^{\prime} v} \quad$ the sea transportation cost of one unit part $s$ from port $k$ to port $k$ ' using vessel $v$.

${ }^{t r P K} C_{p k k^{\prime} v}$ the sea transportation cost of one unit component $p$ from port $k$ to port $k$ ' using vessel $v$.

${ }^{S R K} T_{\text {srkw }} \quad$ the inland transportation time of part $s$ from supplier $r$ to port $k$ using transportation mode $w$.

${ }^{S R O} O_{\text {srow }}$ the inland transportation time of part $s$ from supplier $r$ to plant $o$ using transportation mode $w$.

${ }^{S K O} T_{\text {skow }} \quad$ the inland transportation time of part $s$ from port $k$ to plant $o$ using transportation mode $w$.

${ }^{P R K} T_{\text {prkw }} \quad$ the inland transportation time of component $p$ from supplier $r$ to port $k$ using transportation mode $w$.

${ }^{P O K} T_{\text {pokw }} \quad$ the inland transportation time of component $p$ from plant $o$ to port $k$ using transportation mode $w$.

${ }^{S K} T_{s k k^{\prime} v} \quad$ the sea transportation time of part $s$ from port $k$ to port $k^{\prime}$ using vessel $v$.

${ }^{P K} T_{p k k^{\prime} v} \quad$ the sea transportation time of component $p$ from port $k$ to port $k$ ' using transportation mode $w$. 


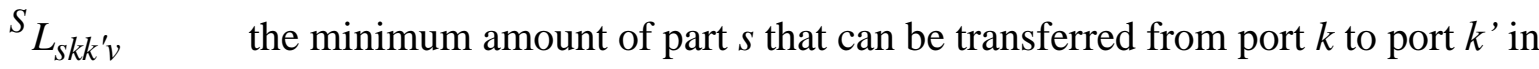 one trip (day) using vessel $v$.
${ }^{P} L_{p k k^{\prime} v} \quad$ the minimum amount of component $p$ that can be transferred from port $k$ to port $k^{\prime}$ in one trip (day) using vessel $v$.

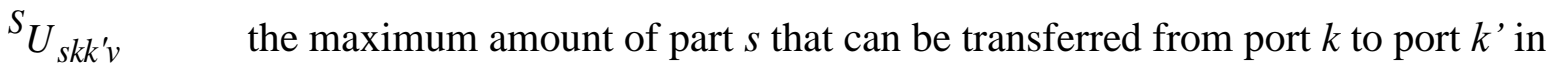 one trip (day) using vessel $v$.
${ }^{P} U_{p k k^{\prime} v} \quad$ the maximum amount of component $p$ that can be transferred from port $k$ to port $k^{\prime}$ in one trip (day) using vessel $v$.
$S_{B_{s r k w}} \quad$ the minimum amount of part $s$ that can be transferred from supplier $r$ to port $k$ in one trip (day) using transportation mode $w$.
${ }^{P} B_{\text {prkw }} \quad$ the minimum amount of component $p$ that can be transferred from supplier $r$ to port $k$ in one trip (day) using transportation mode $w$.

\section{Components and Parts}

$\alpha_{p s} \quad$ the amount of part $s$ required for producing component $p$.

$S_{\rho_{s}} \quad$ area $\left(\mathrm{m}^{2}\right)$ needed for one part $s$ in the inventory.

${ }^{P} \rho_{p} \quad$ area $\left(\mathrm{m}^{2}\right)$ needed for one product $p$ in the inventory.

\section{$\underline{\text { Decision Variables }}$}
${ }^{S R K} x_{\text {srkwt }}$
the amount of part $s$ transferred from supplier $r \in R$ to port $k \in K$ using transportation mode $w \in W$ at period $t$.
$S^{S R O} x_{\text {srowt }}$ the amount of part $s$ transferred from supplier $r \in R$ to plant $o \in O$ using transportation mode $w \in W$ at period $t$.
${ }^{S K O} x_{\text {skowt }}$ the amount of part $s$ transferred from port $k \in K$ to plant $o \in O$ to using transportation mode $w \in W$ at period $t$.
$P R K x_{\text {prkwt }}$ the amount of component $p$ transferred from supplier $r \in R$ to port $k \in K$ using transportation mode $w \in W$ at period $t$.
${ }^{P O K} x_{\text {pokwt }}$ the amount of component $p$ transferred from plant $o \in O$ to port $k \in K$ using transportation mode $w \in W$ at period $t$.
$S K x_{s k k^{\prime} v t} \quad$ the amount of part $s$ transferred from port $k$ to $k^{\prime}$ using vessel $v \in V$ at period $t$.
$P K_{p k k^{\prime} v t} \quad$ the amount of product $p$ transferred from port $k$ to $k^{\prime}$ using vessel $v \in V$ at period $t$.
${ }^{\text {outSR }} f_{\text {srt }} \quad$ the amount of part $s$ sent from supplier $r$ at period $t$. 
${ }^{\text {outPR }} f_{\text {prt }}$ the amount of component $p$ sent from supplier $r$ at period $t$.

${ }^{\text {inSO }} f_{\text {sot }} \quad$ the amount of part $s$ received by plant $o$ at period $t$.

${ }^{\text {outPO }} f_{\text {pot }}$ the amount of component $p$ received by plant $o$ at period $t$.

${ }^{i n S K} f_{s k t} \quad$ the amount of part $s$ received by port $k$ at period $t$.

${ }^{i n P K} f_{p k t} \quad$ the amount of component $p$ received by port $k$ at period $t$.

${ }^{\text {outSK }} f_{\text {skt }} \quad$ the amount of part $s$ sent from port $k$ at period $t$.

${ }^{\text {outPK }} f_{p k t} \quad$ the amount of component $p$ sent from port $k$ at period $t$.

${ }^{\text {outSR }} l_{s r t} \quad$ the inventory level of part $s$ for supplier $r$ at period $t$.

${ }^{\text {outPR }} l_{\text {prt }} \quad$ the inventory level of component $p$ for supplier $r$ at period $t$.

${ }^{i n S O} l_{\text {sot }} \quad$ the inventory level of part $s$ for plant $o$ at period $t$.

${ }^{\text {outPO }} l_{\text {pot }}$ the inventory level of component $p$ for plant $o$ at period $t$.

$S K l_{s k t} \quad$ the inventory level of part $s$ for port $k$ at period $t$.

${ }^{P K} l_{p k t} \quad$ the inventory level of component $p$ for port $k$ at period $t$.

$m_{\text {pot }} \quad$ the amount of product $p$ start to be produced at plant $o$ at period $t$.

$S V y_{s k k^{\prime} v t}=1$ if part $s$ is transferred from port $k$ to port $k^{\prime}$ at period $t$.

$=0$ otherwise

$P V y_{p k k^{\prime} v t}=1$ if component $p$ is transferred from port $k$ to port $k^{\prime}$ at period $t$.

$=0$ otherwise

$S W y_{\text {srkwt }} \quad=1$ if part $s$ is transferred from supplier $r$ to port $k$ at period $t$.

$=0$ otherwise

$P W y_{\text {prkwt }} \quad=1$ if component $p$ is transferred from supplier $r$ to port $k$ at period $t$.

$=0$ otherwise

\section{Objective Function}

Minimizing the total cost which consists of parts/components, inventory, production and transportation sub-costs:

$$
Z=\sum_{r \in R}^{R} T C_{r}+\sum_{o \in O}{ }^{O} T C_{o}+\sum_{k \in K}{ }^{K} T C_{k}+{ }^{T S W} T C+{ }^{T P W} T C+{ }^{T S V} T C+{ }^{T P V} T C
$$

where

${ }^{R} T C_{r} \quad$ the total cost of supplier $r \in R$ 
${ }^{O_{T C}} \quad$ the total cost of plant $o \in O$

${ }^{K} T C_{k} \quad$ the total cost of port $k \in K$

${ }^{T S W} T C$ the total inland transportation cost for all parts

${ }^{T P} W_{T C}$ the total inland transportation cost for all main components

${ }^{T S V} V_{T C}$ the total sea transportation cost for all parts

${ }^{T P V} T C$ the total sea transportation cost for all main components

The problem can be separated into four sub-models namely supplier, plant, port and transportation models, where the detail of each is given as follows:

\section{a) Supplier subset of model}

The total cost consisting of parts/components and holding costs for parts and components for each supplier can be formulated as follows:

$$
\begin{aligned}
{ }^{R} C_{r}=\sum_{s \in S t \in T} \sum_{t}\left({ }^{\text {outSR }} H_{s r} \times{ }^{\text {outSR }} l_{s r t}\right)+\sum_{p \in P} \sum_{t \in T}\left({ }^{\text {outPR }} H_{p r} \times{ }^{\text {outPR }} l_{p r t}\right)+ \\
\sum_{s \in S t \in T} \sum\left({ }^{S R} C_{s r} \times{ }^{\text {out } S R} f_{\text {srt }}\right)+\sum_{p \in P} \sum_{t \in T}\left({ }^{P R} C_{p r} \times{ }^{\text {outPR }} f_{p r t}\right), \forall r \in R
\end{aligned}
$$

Constraints:

$$
\begin{aligned}
& { }^{\text {outSR }} l_{\text {srt }}={ }^{\text {outSR }} l_{s r(t-1)}{ }^{\text {out } S R} f_{\text {srt }}+{ }^{S R} G_{\text {srt }}, \quad \forall s \in S, r \in R, t \in T \\
& { }^{\text {outPR }} l_{\text {prt }}={ }^{\text {outPR }} l_{p r(t-1)}-{ }^{\text {outPR }} f_{p r t}+{ }^{P R} G_{p r t}, \forall p \in P, r \in R, t \in T \\
& { }^{\text {outSR }} l_{\text {srt }} \geq 0,{ }^{\text {outSR }} f_{\text {srt }} \geq 0, \text { integer }, \forall s \in S, t \in T, r \in R \\
& { }_{\text {outPR }} l_{p r t} \geq 0,{ }^{\text {outPR }} f_{\text {prt }} \geq 0, \text { integer }, \forall p \in P, t \in T, r \in R
\end{aligned}
$$

Constraints (3) and (4) ensure inventory balancing of parts and main components respectively. In these constraints, when $(t-1)<0$, variables ${ }^{\text {outSR }} l_{s r(t-1)}$ and ${ }^{o u t P R} l_{p r(t-1)}$ are set to zero.

\section{b) Plant subset of model}

The total cost comprising production and holding costs for parts and components for each plant can be formulated as follows: 


$$
\begin{aligned}
{ }^{o} C_{o}=\sum_{p \in P} \sum_{t \in T}( & \left.A_{p o} \times m_{p o t}\right)+\sum_{s \in S} \sum_{t \in T}\left({ }^{i n S O} H_{s o} \times{ }^{i n S O} l_{s o t}\right)+ \\
& \sum_{p \in P} \sum_{t \in T}\left({ }^{o u t P O} H_{p o} \times{ }^{\text {outPO }} l_{p o t}\right), \quad \forall o \in O
\end{aligned}
$$

Constraints:

$$
\begin{aligned}
& \sum_{t \in T} m_{\text {pot }} \leq{ }^{\operatorname{prod} \text { Cap }}{ }_{\text {po }}, \forall p \in P, o \in R \\
& { }^{i n S O} l_{l_{s o t}}={ }^{i n S O} l_{s o(t-1)}+{ }^{i n S O} f_{s o t}-\sum_{p \in P}\left(\alpha_{p s} \times m_{p o t}\right), \quad \forall s \in S, o \in O, t \in T
\end{aligned}
$$

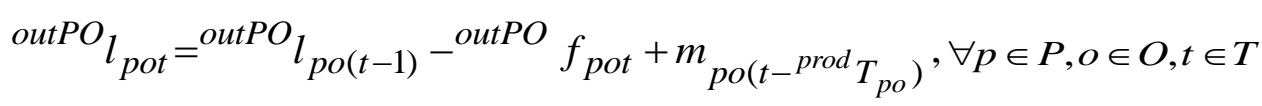

$$
\begin{aligned}
& \sum_{s \in S}\left(S_{\rho_{S}} \cdot{ }^{i n S O} l_{s o t}\right) \leq{ }^{i n v i n O} C_{a p}, \quad \forall o \in O, t \in T \\
& \sum_{p \in P}\left({ }^{P} \rho_{p} \cdot{ }^{\text {outPO }} l_{\text {pot }}\right) \leq{ }^{\text {invoutO }} \mathrm{Cap}_{o}, \quad \forall o \in O, t \in T \\
& { }^{i n S O} l_{l_{\text {sot }} \geq 0,{ }^{i n S O}} f_{\text {sot }} \geq 0 \text {, integer }, \forall s \in S, o \in O, t \in T \\
& { }^{i n P O} l_{\text {pot }} \geq 0,{ }^{i n P O} f_{\text {pot }} \geq 0 \text {, integer }, \forall p \in P, o \in O, t \in T \\
& m_{\text {pot }} \geq 0 \text { and integer }, \forall p \in P, o \in O, t \in T
\end{aligned}
$$

Constraints (8) guarantee that the production rate does not exceed the production capacity. Constraints (9) and (10) make sure that the inventory of parts and main components is balanced in the plants. In these constraints, when $(t-1)<0$, variables ${ }^{o u t S O} l_{s o(t-1)}$ and ${ }^{o u t P O} l_{p o(t-1)}$ are set to zero. Similarly, in Constraints (7), if $\left(t^{{ }^{p r o d}} T_{p o}\right)<0$ then variable $m_{p o\left(t-{ }^{p r o d} T_{p o}\right)}$ is set equal to zero as well. Inventory capacity constraints for parts and main components are presented in Equations (11) and (12) respectively.

\section{c) Port (secondary and installation port) subset of model}

The total cost (holding cost for parts and components) for each port can be formulated as follows:

$$
{ }^{K} T C_{k}=\sum_{s \in S} \sum_{t \in T}\left({ }^{S K} H_{s k} \times{ }^{S K} l_{s k t}\right)+\sum_{p \in P} \sum_{t \in T}\left({ }^{P K} H_{p k} \times{ }^{P K} l_{p k t}\right), \forall k \in K
$$


Constraints:

$$
\begin{aligned}
& { }^{S K} l_{s k t}={ }^{S K} l_{s k(t-1)}+{ }^{i n S K} f_{s k t}{ }^{\text {out } S K} f_{s k t}, \quad \forall s \in S, k \in K, t \in T \\
& { }^{P K} l_{p k t}={ }^{P K} l_{p k(t-1)}+{ }^{i n P K} f_{p k t}-{ }^{\text {outPK }} f_{p k t}-D_{p k t}, \quad \forall p \in P, k \in K, t \in T \\
& \sum_{p \in P}\left({ }^{P} \rho_{p} \times{ }^{P K} l_{p k t}\right)+\sum_{s \in S}\left({ }^{S} \rho_{s} \times{ }^{S K} l_{s k t}\right) \leq{ }^{i n v K} \operatorname{Cap}_{k}, \forall k \in K, t \in T \\
& { }^{S K} l_{s k t} \geq 0,{ }^{i n S K} f_{s k t} \geq 0,{ }^{\text {out } S K} f_{s k t} \geq 0 \text {, integer }, \forall s \in S, k \in K, t \in T \\
& { }^{P K} l_{p k t} \geq 0,{ }^{i n P K} f_{p k t} \geq 0,{ }^{\text {outPK}} f_{p k t} \geq 0 \text {, integer }, \forall p \in P, k \in K, t \in T
\end{aligned}
$$

Constraints (17) and (18) state the inventory balancing of parts and main components in ports respectively. In these constraints, when $(t-1)<0$, variables $S K_{s k(t-1)}$ and ${ }^{P K} l_{p k(t-1)}$ are set equal to zero. Constraints (19) deal with inventory capacity constraint of parts and main components in ports.

\section{d) Transportation subset of model}

The transportation costs can be formulated as follows:

$$
\begin{aligned}
& { }^{T S W} T C=\sum_{s \in S} \sum_{r \in R k \in K} \sum_{w \in W} \sum_{t \in T}\left({ }^{t r S R K} C_{s r k w} \times{ }^{S R K} x_{s r k w t}\right)+ \\
& \sum_{s \in S} \sum_{r \in R} \sum_{\text {o } \in O} \sum_{w \in W} \sum_{t \in T}\left({ }^{t r S R O} C_{\text {srow }} \times{ }^{S R O} x_{\text {srowt }}\right)+ \\
& \sum_{s \in S} \sum_{k \in K} \sum_{o \in O} \sum_{w \in W} \sum_{t \in T}\left({ }^{t r S K O} C_{s k o w} \times{ }^{S K O} x_{\text {skowt }}\right) \\
& { }^{T P W} T C=\sum_{p \in P} \sum_{r \in R k \in K} \sum_{\text {w }} \sum_{w \in W} \sum_{t \in T}\left({ }^{t r P R K} C_{p r k w} \times{ }^{P R K} x_{p r k w t}\right)+ \\
& \sum_{s \in S o \in O} \sum_{k \in K} \sum_{w \in W} \sum_{t \in T}\left({ }^{t r P O K} C_{p o k w} \times{ }^{P O K} x_{p o k w t}\right) \\
& { }^{T S V} T C=\sum_{s \in S k \in K} \sum_{k^{\prime} \in K} \sum_{v \in V t \in T} \sum\left({ }^{t r S K} C_{s k k^{\prime} v} \times{ }^{S K} x_{s k k^{\prime} v t}\right) \\
& { }^{T P V} T C=\sum_{p \in P} \sum_{k \in K} \sum_{k^{\prime} \in K} \sum_{v \in V t \in T} \sum\left(t r P K C_{p k k^{\prime} v} \times{ }^{P K} x_{p k k^{\prime} v t}\right)
\end{aligned}
$$

Constraints: 


$$
\begin{aligned}
& { }^{\text {outSR }} f_{\text {srt }}=\sum_{o \in O} \sum_{w \in W}^{S R O} x_{\text {srowt }}+\sum_{k \in K} \sum_{w \in W}^{S R K} x_{\text {srkwt }}, \forall s \in S, r \in R, t \in T
\end{aligned}
$$

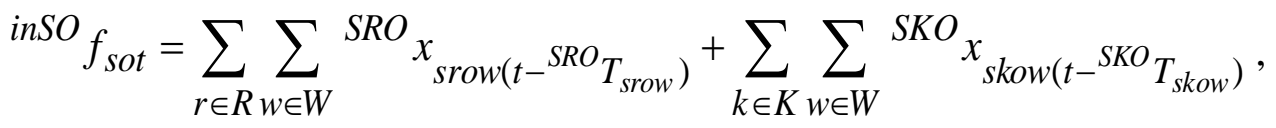

$$
\begin{aligned}
& \forall s \in S, o \in O, t \in T \\
& { }^{\text {outPO }} f_{\text {pot }}=\sum_{k \in K} \sum_{w \in W}^{P O K} x_{\text {pokwt }}, \forall p \in P, o \in O, t \in T
\end{aligned}
$$

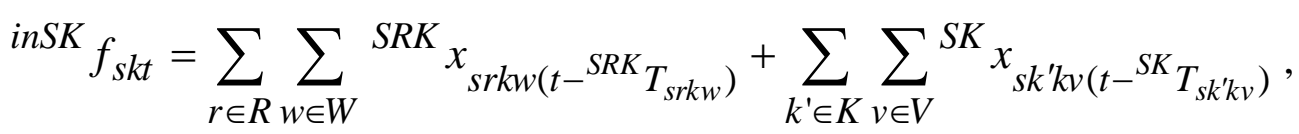

$$
\begin{aligned}
& \forall s \in S, k \in K, t \in T \\
& { }^{\text {outSK }} f_{s k t}=\sum_{o \in O} \sum_{w \in W}{ }^{S K O} x_{s k o w t}+\sum_{k^{\prime} \in K} \sum_{v \in V}^{S K} x_{s k k^{\prime} v t}, \forall s \in S, k \in K, t \in T \\
& \left.{ }^{i n P K} f_{p k t}=\sum_{o \in O} \sum_{w \in W}{ }^{P O K} x_{p o k w(t-}^{P O K} T_{p o k w}\right)+\sum_{k^{\prime} \in K} \sum_{v \in V}{ }^{P K} x_{p k^{\prime} k v\left(t-{ }^{P K} T_{k^{\prime} k v}\right)}+
\end{aligned}
$$

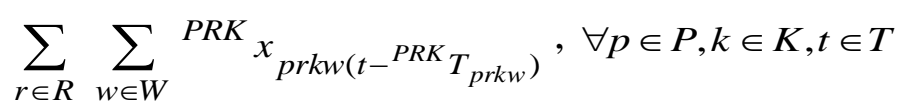

$$
\begin{aligned}
& { }^{\text {outPK }} f_{p k t}=\sum_{k^{\prime} \in K} \sum_{v \in V}{ }^{P K} x_{p k k^{\prime} p t}+\sum_{f \in F} D_{p k f}, \forall p \in P, k \in K, t \in T
\end{aligned}
$$

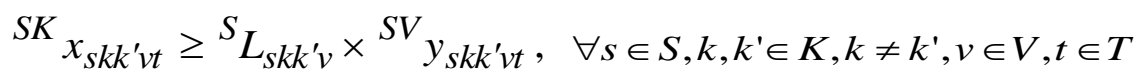

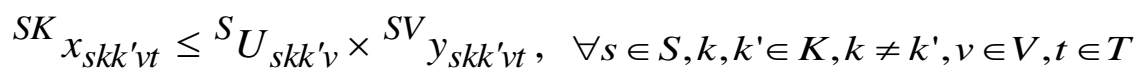

$$
\begin{aligned}
& { }^{P K} x_{p k k^{\prime} v t} \geq{ }^{P} L_{p k k^{\prime} v} \times{ }^{P V} y_{p k k^{\prime} v t}, \quad \forall p \in P, k, k^{\prime} \in K, k \neq k^{\prime}, v \in V, t \in T \\
& { }^{P K} x_{p k k^{\prime} v t} \leq{ }^{P} U_{p k k^{\prime} v} \times{ }^{P V} y_{p k k^{\prime} v t}, \quad \forall p \in P, k, k^{\prime} \in K, k \neq k^{\prime}, v \in V, t \in T \\
& S R X_{x_{s r k w t}} \leq S_{B_{s r k w} \times}{ }^{S W} y_{s r k w t}, \quad \forall s \in S, r \in R, k \in K, w \in W, t \in T \\
& { }^{P R K} x_{p r k w t} \leq{ }^{P} B_{p r k w} \times P W_{y_{p r k w t}}, \forall p \in P, r \in R, k \in K, w \in W, t \in T \\
& S R K x_{\text {srkwt }} \geq 0 \text {, integer }, \forall s \in S, r \in R, k \in K, w \in W, t \in T \\
& S R O x_{\text {srowt }} \geq 0 \text {, integer }, \forall s \in S, r \in R, o \in O, w \in W, t \in T \\
& S K O_{x_{\text {skowt }}} \geq 0 \text {, integer }, \forall s \in S, k \in K, o \in O, w \in W, t \in T \\
& { }^{P R K} x_{\text {prkwt }} \geq 0 \text {, integer }, \forall p \in P, r \in R, k \in K, w \in W, t \in T \\
& { }^{P O K} x_{\text {pokwt }} \geq 0 \text {, integer }, \forall p \in P, o \in O, k \in K, w \in W, t \in T \\
& { }^{S K} x_{s k k^{\prime} v t} \geq 0 \text {, integer, } \forall s \in S, k, k^{\prime} \in K, v \in V, t \in T \\
& { }^{P K} x_{p k k^{\prime} v t} \geq 0 \text {, integer }, \forall p \in P, k, k^{\prime} \in K, v \in V, t \in T \\
& S V y_{s k k^{\prime} v t}=\{0,1\}, \forall s \in S, k, k^{\prime} \in K, v \in V, t \in T
\end{aligned}
$$




$$
\begin{aligned}
& P V y_{p k k^{\prime} v t}=\{0,1\}, \forall p \in P, k, k^{\prime} \in K, v \in V, t \in T \\
& S W y_{s r k w t}=\{0,1\}, \forall s \in S, r \in R, k \in K, w \in W, t \in T \\
& P W y_{\text {prkwt }}=\{0,1\}, \forall p \in P, r \in R, k \in K, w \in W, t \in T
\end{aligned}
$$

Equations (22) and (23) calculate the total inland transportation costs for parts and main components respectively whereas Equations (24) and (25) determine the total sea transportation costs for parts and main components respectively. Constraints (26) - (32) ensure the flow balancing for parts and main components in suppliers, plants and ports. These constraints also determine the amount of components/parts transferred from one node to another. Constraints (33) - (36) state the minimum and maximum amount of parts and components that can be transferred by a vessel in one trip (day). Constraints (37) - (38) indicate the maximum amount of parts and components transferred by an inland transportation mode in one trip (day).

\section{Case study}

This section presents a set of solutions generated by the proposed models described in section 3. In this section, an example of the usage of the combined AHP-ILP model to produce supply chain solutions for the West Gabbard wind farm located in the Southern part of the North Sea is shown. The offshore wind energy is emerging as a major energy source in the UK's energy portfolio. The southern part of the North Sea accommodates a large number of wind farms and therefore the case study focuses on an offshore wind farm in this location as it gives a realistic scenario. In section 4.1 we present the experiments of the AHP model for the selection of the most suitable installation port and in section 4.2 the results of the ILP model are discussed. As West Gabbard wind farm still requires planning permission, there is no existing/current solutions for this case study. Moreover, there are no solutions available in the literature to compare a set of solutions obtained by the proposed models.

\subsection{Experiments on the AHP Model}

In this subsection the case study related to the port selection model is presented. The problem is defined as the decision makers' choice of selecting the most suitable port for their wind farm based on criteria described in section 3.1. Five ports were chosen as candidate ports for hosting the installation phase of the wind farm based on their previous experience and 
involvement in the offshore wind sector. The UK based ports are Port of Harwich Navyard, Port of Hull, Able Humber Port, and Port of Great Yarmouth and the Port of Oostende is located in Belgium. The Data related to each criterion for the candidate ports has been obtained using publicly available data sources.

The final results related to suitability scores of the installation ports using the AHP model are as follows:

1. Port of Oostende : 0.63

2. Port of Hull : 0. 59

3. Able Humber port : 0.57

4. Harwich Navyard : 0.49

5. Port of Great Yarmouth : 0.40

The Port of Oostende has obtained the highest suitability score. Based on this result, The Port of Oostende is used in the ILP model as the destination port to which the components are sent from different suppliers across Europe.

\subsection{Experiments on the supply chain optimisation model}

In this subsection, the solution of the "transport to installation ports" model is presented. The solution of the model will answer the following questions: Which supplier will deliver which components/parts (When and how many units)? The main input for this model is the installation schedule. As the port selection model selected the port of Oostende as the most suitable installation port, we use this port as the single installation port in this case study. We focus on three main components, namely the tower, blades, and nacelle. The suppliers of those components are given in Table 3. The table shows the location of suppliers and their coordinates along with the type of component that they produce. We estimate the cost of components for each supplier based on Fingersh et al. (2006). Table 4 presents the data of the ports used in the model.

Table 3: Supplier data

\begin{tabular}{llllll}
\hline ID & Location & Country & Component & Latitude & Longitude \\
\hline S1 & Grafenhaininchen & Germany & Tower & 51.72908889 & 12.44547222 \\
S2 & Bremen & Germany & Tower & 53.17588056 & 8.598841667 \\
S3 & Cuxhaven & Germany & Tower & 53.84640278 & 8.736583333 \\
S4 & Varde & Denmark & Tower & 55.61197222 & 8.470322222
\end{tabular}




\begin{tabular}{llllll} 
S5 & Vejlevej & Denmark & Tower & 55.90661111 & 9.194872222 \\
S6 & Nassau & Germany & Tower & 50.316234 & 7.784168 \\
S7 & Stassfurt & Germany & Tower & 51.86274 & 11.590139 \\
S8 & Wurzen & Germany & Tower & 51.37749 & 12.75244983 \\
S9 & Emden & Germany & Tower & 53.357635 & 7.211913 \\
S10 & Aalborg & Denmark & Tower & 57.05566111 & 10.03741944 \\
S11 & Lindo & Denmark & Tower & 55.46863889 & 10.52971389 \\
S12 & Lubmin & Germany & Tower & 54.13845 & 13.667275 \\
S13 & Szczecin & Poland & Tower & 53.44873333 & 14.51631111 \\
S14 & Schewerin & Germany & Tower & 53.65383056 & 11.40448056 \\
S15 & Vaerksvej & Denmark & Tower & 55.02908583 & 9.317021833 \\
S16 & Stade & Germany & Blades & 53.65751983 & 9.492969833 \\
S17 & Lemwerder & Germany & Blades & 53.16155583 & 8.620525 \\
S18 & Bremerhaven & Germany & Blades & 53.509607 & 8.592724 \\
S19 & Aalborg & Denmark & Blades & 57.041308 & 10.030378 \\
S20 & Saint Nazaire & France & Nacelle & 47.292515 & 2.187063 \\
S21 & Bremerhaven & Germany & Nacelle & 53.498516 & 8.590439833 \\
S22 & Emden & Germany & Nacelle & 53.338599 & 7.214197833 \\
S23 & Bremerhaven & Germany & Nacelle & 53.49517983 & 8.587529833 \\
\hline
\end{tabular}


Table 4: Port data

\begin{tabular}{lllll}
\hline PortID & Location & Country & Latitude & Longitude \\
\hline P0 & Oostende & Belgium & 51.22 & 2.93 \\
P1 & Aalborg & Denmark & 57.05566111 & 10.03741944 \\
P2 & Bremerhaven & Germany & 53.498516 & 8.590439833 \\
P3 & Wilhelmshaven & Germany & 53.513014 & 8.143077 \\
P4 & Rostock & Germany & 54.149114 & 12.106659 \\
P5 & Hvide sande & Denmark & 56 & 8.1 \\
\hline
\end{tabular}

The computational experiments were carried out using 11 randomly generated installation schedules. We vary the number of turbines $(N)$ to be installed from 80 to 100 with an increment of 2 which corresponds to a medium to large wind farm by current standards. We also set the number of periods/days (planning horizon) to $N$. Table 5 shows an example of the installation schedule for $N=100$. This figure has been suggested based on the current industry practice of offshore wind installation in the summer period. The table presents the number of turbines to be installed per period. Based on this schedule, the components must be available in the installation port to avoid delay. However, the component inventory needs also to be optimised as the holding cost of these large, heavy components is relatively high. The transportation cost for each component is based on the distance and we set the maximum transportation cost to $20 \%$ of the component cost. We also set the holding/inventory cost for each component to $20 \%$ of the component cost per year. In the model, it is assumed that size of the ports is large enough to store the components. Therefore, the capacity constraints of the ports are not considered. The limited capacity port layout optimisation for the installation port has been addressed by Irawan et al. (2017).

Table 5: Installation Schedule for $N=100$

\begin{tabular}{cccccccc}
\hline Day (qty) & Day (qty) & Day (qty) & Day (qty) & Day (qty) & Day (qty) & Day (qty) & Day (qty) \\
\hline $10(1)$ & $30(1)$ & $43(1)$ & $54(2)$ & $63(1)$ & $72(2)$ & $81(1)$ & $90(1)$ \\
$13(2)$ & $31(1)$ & $44(1)$ & $55(2)$ & $64(2)$ & $73(2)$ & $82(1)$ & $91(1)$ \\
$16(2)$ & $32(1)$ & $45(2)$ & $56(2)$ & $65(1)$ & $74(2)$ & $83(1)$ & $92(1)$ \\
$19(2)$ & $33(1)$ & $47(2)$ & $57(1)$ & $66(1)$ & $75(1)$ & $84(1)$ & $93(1)$ \\
$21(1)$ & $36(2)$ & $48(2)$ & $58(1)$ & $67(1)$ & $76(2)$ & $85(1)$ & $94(1)$ \\
$23(1)$ & $39(1)$ & $50(2)$ & $59(2)$ & $68(1)$ & $77(2)$ & $86(1)$ & $95(1)$ \\
$25(1)$ & $40(2)$ & $51(2)$ & $60(2)$ & $69(1)$ & $78(2)$ & $87(1)$ & $96(1)$ \\
$28(1)$ & $41(2)$ & $52(2)$ & $61(2)$ & $70(2)$ & $79(1)$ & $88(1)$ & $97(1)$ \\
$29(1)$ & $42(1)$ & $53(1)$ & $62(2)$ & $71(2)$ & $80(1)$ & $89(1)$ & $98(1)$ \\
\hline
\end{tabular}


Table 6 shows the summary of the computational results of the model which is solved by an exact mathematical programming method (using IBM ILOG CPLEX version 12.63). The tests were executed on a PC with an Intel Core i5 CPU @ 3.20GHz processor, 8.00 GB of RAM and under Windows 7. In this study, the CPU time for solving each instance is limited to one hour so upper bound (UB) and the lower bound (LB) can be attained. In addition, \%gap between the UB and the LB values is given which is formulated as follows:

$$
\% G a p=\frac{U B-L B}{U B} \times 100
$$

Table 6: The summary of the computational results for the supply chain model

\begin{tabular}{|c|c|c|c|c|c|c|}
\hline \multirow{2}{*}{ Instance } & \multirow{2}{*}{$N$} & \multirow{2}{*}{$|T|$} & \multicolumn{4}{|c|}{ Exact Method using CPLEX Ver 12.63 (CPU = 1 hour) } \\
\hline & & & UB & LB & $\%$ gap & CPU time (s) \\
\hline 1 & 80 & 80 & $75,697,402$ & $75,623,683$ & 0.0974 & 3,608 \\
\hline 2 & 82 & 82 & $77,695,881$ & $77,623,859$ & 0.0927 & 3,611 \\
\hline 3 & 84 & 84 & $79,601,561$ & $79,529,925$ & 0.0900 & 3,620 \\
\hline 4 & 86 & 86 & $81,637,475$ & $81,524,990$ & 0.1378 & 3,625 \\
\hline 5 & 88 & 88 & $83,703,971$ & $83,627,666$ & 0.0912 & 3,634 \\
\hline 6 & 90 & 90 & $85,739,172$ & $85,661,901$ & 0.0901 & 3,642 \\
\hline 7 & 92 & 92 & $87,677,435$ & $87,596,685$ & 0.0921 & 3,638 \\
\hline 8 & 94 & 94 & $89,692,508$ & $89,649,551$ & 0.0479 & 3,625 \\
\hline 9 & 96 & 96 & $91,649,381$ & $91,608,842$ & 0.0442 & 3,633 \\
\hline 10 & 98 & 98 & $93,450,198$ & $93,440,853$ & 0.0100 & 2,894 \\
\hline 11 & 100 & 100 & 95,391,990 & $95,382,451$ & 0.0100 & 1,993 \\
\hline \multicolumn{5}{|c|}{ Average } & 0.0730 & 3,411 \\
\hline
\end{tabular}

Table 6 shows that the exact method (CPLEX) was able to obtain good solutions with an average $\%$ gap of $0.0730 \%$. The bold face in the table indicates that the optimal solution is obtained. Out of 11 instances, CPLEX found two optimal solutions for Instances 10 and 11 within one hour. According to the table, the total cost increases with the number of turbines $(N)$. In these experiments, we set the minimum and maximum number of towers that can be transported by a vessel to 8 and 12 respectively except from the port of Lindo (Denmark) to the port of Aalborg (Denmark). We also set the maximum number of towers that can be transferred by an inland transportation mode (truck or train) to 2 . At the beginning of period, it is assumed that the installation port has already 5 units of each component. Here, the inventory cost is only considered for the installation port.

Table 7 presents the flows of components from suppliers to the installation port in the optimal solution for $N=100$. The table shows the starting period and the quantity of towers to 
be transferred from suppliers to the installation port. According to Table 7, suppliers located in Wurzen, Stade, and Saint Nazaire provide the most number of towers, blades, and nacelles respectively. The table shows that Port of Hvide sande is most frequently used as a secondary port to transport the towers to the installation port whereas for blade and nacelle, it is Port of Bremerhaven.

Table 7: The movement of components from suppliers to the installation port for $N=100$

\begin{tabular}{|c|c|c|}
\hline Flows of component & Period/day (quantity) & $\begin{array}{c}\text { Total } \\
\text { Qty }\end{array}$ \\
\hline \multicolumn{3}{|l|}{ Tower } \\
\hline Grafenhaininchen - Oostende & $31(1) ; 55(1) ; 63(1) ; 83(1) ; 84(1) ; 86(1) ; 92(1) ; 96(1)$ & 8 \\
\hline Bremen - Bremerhaven - Oostende & $41(2) ; 42(2) ; 69(2) ; 70(2)$ & 8 \\
\hline Cuxhaven - Bremerhaven - Oostende & $41(2) ; 42(2) ; 69(2) ; 70(2)$ & 8 \\
\hline Varde - Hvide sande - Oostende & $47(2) ; 48(2) ; 54(2) ; 55(2)$ & 8 \\
\hline Vejlevej - Hvide sande - Oostende & $47(1) ; 48(2) ; 54(2) ; 55(2)$ & 7 \\
\hline Nassau - Oostende & $18(2) ; 20(1) ; 31(1) ; 66(1) ; 83(1) ; 92(1) ; 95(1)$ & 8 \\
\hline Stassfurt - Oostende & $34(2) ; 64(1) ; 85(1) ; 89(1) ; 90(1) ; 95(1)$ & 7 \\
\hline Wurzen - Oostende & $21(1) ; 23(1) ; 26(1) ; 27(1) ; 28(1) ; 29(1) ; 87(1) ; 88(1) ; 93(1)$ & 9 \\
\hline Emden - Wilhelmshaven - Oostende & $72(2) ; 73(2) ; 74(2) ; 75(2)$ & 8 \\
\hline Aalborg - Oostende & $35(2) ; 36(2) ; 64(2) ; 65(2)$ & 8 \\
\hline Lindo - Aalborg - Oostende & $34(4) ; 63(4)$ & 8 \\
\hline Vaerksvej - Hvide sande - Oostende & $47(2) ; 48(2) ; 54(2) ; 55(2)$ & 8 \\
\hline \multicolumn{3}{|l|}{ Blade } \\
\hline Stade - Bremerhaven - Oostende & 28(3); 38(3); 51(3); 56(3); 61(3); 72(3); 73(3); 80(3); 88(3); & 27 \\
\hline Lemwerder - Bremerhaven -Oostende & $28(3) ; 38(3) ; 51(3) ; 56(3) ; 61(3) ; 73(3) ; 80(3) ; 87(2) ; 88(3)$ & 26 \\
\hline Bremerhaven - Oostende & $29(2) ; 39(3) ; 52(2) ; 57(3) ; 62(3) ; 74(1) ; 81(2)$ & 16 \\
\hline Aalborg - Oostende & $16(8) ; 45(9) ; 68(9)$ & 26 \\
\hline \multicolumn{3}{|l|}{ Nacelle } \\
\hline Saint Nazaire - Oostende & $\begin{array}{l}18(2) ; 20(1) ; 22(1) ; 24(1) ; 27(1) ; 28(1) ; 29(1) ; 30(1) ; 31(1) ; \\
32(1) ; 35(2) ; 38(1) ; 44(1) ; 55(1) ; 67(1) ; 68(1) ; 73(2) ; 95(1) ; \\
95(1) ; 96(1) ; 97(1) ;\end{array}$ & 23 \\
\hline Bremerhaven (S21) - Oostende & $50(5) ; 55(8) ; 68(8) ; 73(8)$ & 29 \\
\hline Emden - Wilhelmshaven - Oostende & $36(2) ; 37(3) ; 38(3) ; 84(2) ; 85(3) ; 86(3)$ & 16 \\
\hline Bremerhaven (S23) - Oostende & $45(8) ; 50(3) ; 60(8) ; 78(8)$ & 27 \\
\hline
\end{tabular}

Table 8 shows the cost breakdown for $N=100$ where three types of costs are presented, namely unit components, inventory and transportation costs. According to the table, the total components cost (tower, blade and nacelle) contributes the highest share to the total cost which is more than $90 \%$. The total transportation cost (inland and sea transport) makes up to $9 \%$ of total cost, below the $20 \%$ limit. The inventory cost provides the smallest portion to the total cost as this cost occurs only in the installation port. 
Table 8: The total cost breakdown for $N=100$

\begin{tabular}{lll}
\hline Item & Cost & Percentage \\
\hline Transportation & $8,631,438.27$ & 9.05 \\
Inventory & $137,857.10$ & 0.14 \\
Components & $86,622,695.00$ & 90.81 \\
\hline Total & $95,391,990.36$ & 100.00
\end{tabular}

Table 9 presents the inventory and transportation costs breakdown by component for $N=100$. Based on the figure, the component which contributes the largest portion to the inventory and transportation costs is the Nacelle (up to 70\%). The Nacelle is the most expensive component compared to the blade and tower. In our study, the transportation and inventory costs are calculated mainly based on the cost of the components.

Table 9: The breakdown of inventory and transportation costs for $N=100$

\begin{tabular}{lccccc}
\hline & \multicolumn{2}{c}{ Transportation } & & \multicolumn{2}{c}{ Inventory } \\
\cline { 2 - 3 } \cline { 5 - 6 } \cline { 5 - 6 } & Cost & Percentage & & Cost & Percentage \\
\hline Tower & $1,550,103.92$ & 17.96 & & $21,352.63$ & 15.49 \\
Blade & $1,043,505.96$ & 12.09 & & $30,654.10$ & 22.24 \\
Nacelle & $6,037,828.38$ & 69.95 & & $85,850.36$ & 62.27 \\
\hline Total & $8,631,438.27$ & 100.00 & & $137,857.10$ & 100.00
\end{tabular}

\subsection{Discussion and Managerial Implications}

The experimental results in Sections 4.1 and 4.2 have been divided into two parts, port selection and supply chain optimisation. It is clear that these two aspects are strongly connected, as a sub-optimal choice of port with respect to stakeholder preferences will lead to inefficiencies in the resulting supply chain. The optimal port for the given example (West Gabbard) is in a different country to the territorial waters of the wind farm site, with parts sourced from multiple third country destinations. This demonstrates the need to consider all potential options when considering the selection of an installation port rather than being constrained by national boundaries. This is particularly true of areas like the North Sea where multiple wind farms in multiple countries' territorial waters are planned in relative close proximity. The supply chain optimisation computational times, along with the models given in Section 3, demonstrate the complexity of the wind supply chain planning process. This in turn 
implies that sophisticated optimisation modelling and solution techniques need to be employed in order for managers to obtain efficient wind sector supply chain solutions. The disparity between transportation and inventory costs throughout Section 4.2 shows the need to focus on future attention on innovations that improve efficiency in the transportation aspect, particularly with respect to nacelles. The disparity may also lead managers to consider innovations that trade off additional inventory costs for more cost effective transportation solutions.

\section{Conclusion and suggestions}

This paper studies the supply chain for the installation phase of offshore wind projects and practical models for component transportation and port selection are proposed that allow offshore wind developers to schedule the construction of the wind farm. The primary aim of this research is to help decision makers in the offshore wind sector in supply chain planning and optimization that can eventually lead to lower transportation cost. Due to the complex logistics and large size of the offshore wind components, modelling the component flow in the most efficient manner is necessary for minimizing the supply chain cost. Combining the AHP and ILP methods produces an integrated supply chain solution for the transportation of the components from the suppliers to the installation port. Furthermore, the results for the West Gabbard case application suggest that a large part of the logistics costs are related to the nacelle's transportation and inventory cost and therefore more attention may be given to developing the supply chain of this component. The model proposed in this paper is also applicable for construction of other offshore renewable energies such as tidal arrays where underwater turbines are used for extracting the tidal energy.

The main focus of this research has been on the choice of port and the subsequent inland and sea transportation of the components and the offshore installation of the wind farms have not been considered. Future research can be directed at development of integrated supply chain models for the inclusion of the offshore installation of the components to produce a fully integrated supply chain decision support tool for the offshore wind energy sector. 


\section{Acknowledgments}

The research leading to these results has received funding from the European Union Seventh Framework Programme under the agreement SCP2-GA-2013-614020 (LEANWIND: Logistic Efficiencies And Naval architecture for Wind Installations with Novel Developments).

\section{References}

1. Abedi, A., and W. Zhu. 2017. "An optimisation model for purchase, production and distribution in fish supply chain - a case study." International Journal of Production Research 55 (12): 3451-3464.

2. Akbari, N., C. A. Irawan., D. F. Jones, and D. Menachof. 2016. "A port suitability assessment model for the operations and maintenance phase of the offshore wind industry." Proceedings of the $3^{\text {rd }}$ international conference on Green Supply Chain, July 11-13, London, UK.

3. Akbari, N., C. A. Irawan., D. F. Jones, and D. Menachof. 2017. "A multi-criteria port suitability assessment for developments in the offshore wind industry." Renewable Energy 102, 118-133.

4. Archer, C. L., H. P. Simao, W. Kempton, W. B. Powell., and M. J. Dvorak. 2017. "The challenge of integrating offshore wind power in the U.S. electric grid. Part I: Wind forecast error." Renewable Energy 103: 346-360.

5. Barbarosoglu, G., and D. Ozgur. 1999. "Hierarchical design of an integrated production and 2-echelon distribution system". European Journal of Operational Research 118: 464484.

6. Bilgen, B., and I. Ozkarahan. 2007. "A mixed-integer linear programming model for bulk grain blending and shipping”. International Journal of Production Economics 107: 555571 .

7. Cárdenas-Barrón, L. E., and G. Treviño-Garza. 2014. "An optimal solution to a three echelon supply chain network with multi-product and multi-period." Applied Mathematical Modelling 38: 1911-1918.

8. Chou, C. C. 2010. "AHP model for the container port choice in the multiple-ports region." Journal of Marine Science and Technology 18 (2): 221-232.

9. Cohen, M. A., and H. L. Lee. 1988. "Strategic analysis of integrated productiondistribution systems: Models and methods." Operations Research 36: 216-228.

10. D'Amico, F. 2012. "Offshore wind super clusters-New opportunities for Italian ports" (Doctoral thesis). Universita degli studi G. D'Annunzio di Chieti-Pescara.

11. Eksioglu, S. D., H. E. Romeijn, and P. M. Pardalos. 2006. "Cross-facility management of production and transportation planning problem". Computers and Operations Research 33: 3231-3251.

12. Fahimnia, B., J. Sarkis, J. Boland, M. Reisi, and M. Goh. 2015. "Policy insights from a green supply chain optimisation model." International Journal of Production Research 53: 6522-6533. 
13. Fetanat, A., and E. Khorasaninejad. 2015. "A novel hybrid MCDM approach for offshore wind farm site selection: A case study of Iran." Ocean \& Coastal Management 109: 17 28.

14. Fingersh, L., M. Hand, and A. Laxson. 2006. "Wind Turbine Design Cost and Scaling Model." Technical Report NREL/TP-500-40566.

15. Galvez, D., A. Rakotondranaivo, L. Morel, M. Camargo, and M. Fick. 2015. "Reverse logistics network design for a biogas plant: An approach based on MILP optimization and Analytical Hierarchical Process (AHP)". Journal of Manufacturing Systems 37 (3): 616623.

16. Gen, M. S., and A. Syarif. 2005. "Hybrid genetic algorithm for multi-time period production/distribution planning". Computers and Industrial Engineering 48: 799-809.

17. Geoffrion, A. M., and G. W. Graves. 1974. "Multicommodity distribution system design by benders decomposition." Management Science 20: 822-844.

18. Goetschalckx, M., C. J. Vidal, and K. Dogan. 2002. "Modeling and design of global logistics systems: a review of integrated strategic and tactical models and design algorithms." European Journal of Operational Research 143: 1-18.

19. He, Y., and X. Chen. 2009. "Wind turbine generator systems. The supply chain in China: Status and problems." Renewable Energy 34: 2892-2897.

20. Heffron, R. J., and D. McCauley. 2014. "Achieving sustainable supply chains through energy justice." Applied Energy 123: 435-437.

21. Hobbs, B. F. 1986. "What can we learn from experiments in multiobjective decision analysis?" IEEE Transactions on Systems, Manufacturing, and Cybernetics 16 (3): 384394.

22. Hwang, C. L., and K. Yoon. 1981. "Multiple Attributes Decision Making Methods and Applications". Springer, Berlin Heidelberg.

23. Irawan, C. A., X. Song., D. Jones, and N. Akbari. 2017. "Layout optimisation for an installation port of an offshore wind farm." European Journal of Operational Research 259 (1): 67-83.

24. Jang, Y. J., S.Y. Jang, B. M. Chang, and J. Park. 2002. "A combined model of network design and production/distribution planning for a supply network". Computers and Industrial Engineering 43: 263-281.

25. Khalili, S. M., F. Jolai and S. A. Torabi. 2017. "Integrated production-distribution planning in two-echelon systems: a resilience view". International Journal of Production Research 55(4): 1040-1064.

26. Lozano-Minguez, E. A. J. Kolios, and F. P. Brennan. 2011. "Multi-criteria assessment of offshore wind turbine support structures". Renewable Energy 36(11): 2831-2837.

27. Mcdonald, C.M., and I. A. Karimi. 1997. "Planning and scheduling of parallel semi continuous processes. 1. Production planning". Industrial and Engineering Chemistry Research 36: 2691-2700.

28. Mula, J., D. Peidro, M. Diaz-Madronero, and E. Vicens. 2010. "Mathematical programming models for supply chain production and transport planning." European Journal of Operational Research 204: 377-390.

29. Mulliner, E., N. Malys, and V. Maliene. 2016. "Comparative analysis of MCDM methods for the assessment of sustainable housing affordability”. Omega 59: 146-156. 
30. Ozgen, D., and B. Gulsun. 2014. "Combining possibilistic linear programming and fuzzy AHP for solving the multi-objective capacitated multi-facility location problem". Information Sciences 268: 185-201.

31. Park, Y. B. 2005. "An integrated approach for production and distribution planning in supply chain management”. International Journal of Production Research 43: 1205-1224.

32. Poulsen, T., and R. Lema. 2017. "Is the supply chain ready for the green transformation? The case of offshore wind logistics." Renewable and sustainable energy reviews 73: 758771.

33. Rabbani, A., M. Zamani, A. Yazdani-Chamzini, and E. Kazimieras Zavadskas. 2014. "Proposing a new integrated model based on sustainability balances scorecard (SBSC) and MCDM approaches by using linguistic variables for the performance evaluation of oil producing companies". Expert systems with applications 41 (16): 7316-7327.

34. Romo, F., A. Tomasgard, L. Hellemo, M. Fodstad, B. H. Eidesen, and B. Pedersen. 2009. Optimizing the Norwegian Natural gas production and transport. Interfaces 39 (1): 46-56.

35. Saaty, T. L. 2000 "Fundamentals of Decision Making and Priority Theory with the Analytic Hierarchy Process". RWS Publications, Pittsburgh.

36. Snyder, B., and M. J. Kaiser. 2009. "A comparison of offshore wind development in Europe and the US: patterns and drivers of development". Applied Energy 86: 1845-1856.

37. Tang, L., K. Jing, and J. He. 2013. "An improved ant colony optimisation algorithm for three-tier supply chain scheduling based on networked manufacturing." International Journal of Production Research 51: 3945-3962.

38. Ugboma, C., O. Ugboma, and I. C. Ogwude. 2006. "An analytical hierarchy process (AHP) approach to port selection decisions-empirical evidence from Nigerian ports." Maritime Economics \& Logistics 8: 251-266.

39. Vasileiou, M., E. Loukogeorgaki, and D. G. Vagiona. 2017. "GIS-based multi-criteria decision analysis for site selection of hybrid offshore wind and wave energy systems in Greece". Renewable and sustainable energy reviews 73: 745-757.

40. Velasquez, M, P. T. Hester. 2013. "An analysis of Multi-criteria decision making methods". International Journal of Operations Research 10 (2): 56-66.

41. Verderame, P. M., and C. A. Floudas. 2009. "Operational planning framework for multisite production and distribution networks." Computers \& Chemical Engineering 33: $1036-1050$.

42. Wedley, W. C. 1990. "Combining qualitative and quantitative factors- an analytical hierarchy approach”. Socio-Economic Planning Sciences 24 (1): 57-64.

43. Wee, H., W. Yang, C. Chou, and M. V. Padilan. 2012. "Renewable energy supply chains, performance, application barriers, and strategies for further development." Renewable and Sustainable Energy Reviews 16: 5451-5465.

44. Wilkinson, S. J., A. Cortier, N. Shah, and C. C. Pantelides. 1996. "Integrated production and distribution scheduling on a Europe-wide basis". Computers \& Chemical Engineering 20: $1275-1280$.

45. Wüstemeyer, C., R. Madlener, and D. W. Bunn. 2015. "A stake holder analysis of divergent supply-chain trends for the European onshore and offshore wind installations." Energy Policy 80: 36-44.

46. Yuan, J., S. Sun, J. Shen, Y. Xu, and C. Zhao. 2014. "Wind power supply chain in China." Renewable and Sustainable Energy Reviews 39: 356-369. 
47. Yunna, W., Z. Jinying, Y. Jianping, G. Shuai, and Z. Haobo. 2016. "Study of decision framework of offshore wind power station site selection based on ELECTRE-III under intuitionistic fuzzy environment: A case of China". Energy Conversion and Management 113: $66-81$.

48. Zanakis, S. H., A. Solomon, N. Wishart, and S. Dublish. 1998. "Multi-attribute decision making: A simulation comparison of select methods". European Journal of Operation Research 107: 507-529.

49. Zavadskas, E. K., Z. Turskis, and V. Bagocius. 2015. "Multi-criteria selection of a deep water port in the Eastern Baltic Sea". Applied Soft Computing 26: 180-192.

50. Zhao, Z., Y. Tian, and G. Zillante. 2014. "Modeling and evaluation of the wind power industry chain: A China study." Renewable and Sustainable Energy Reviews 31: 397-406.

51. Tetra Tech, Port and infrastructure analysis for offshore wind energy development, 2010. http://images.masscec.com/uploads/attachments/Port\%20and\%20Infrastructure\%20Anal ysis\%20for\%200ffshore\%20Wind\%20Energy\%20Development/MA\%20Port\%20Study \%20Final\%20Report 4-20-10.pdf (Accessed 04.11.2014)

52. Garrad Hassan America, Assessment of ports for offshore wind development in the United States, 2014.

http://energy.gov/sites/prod/files/2014/03/f14/Assessment\%20of\%20Ports\%20for\%200f fshore\%20Wind\%20Development\%20in\%20the\%20United\%20States_1.pdf, 2014 (accessed 12.09.2014).

53. Department of Energy and Climate Change (DECC). Electricity Generation costs, 2013. https://www.gov.uk/government/uploads/system/uploads/attachment_data/file/269888/13 1217_Electricity_Generation_costs_report_December_2013_Final.pdf, 2013_accessed 02.02.2015).

54. Wind Europe, 2016. "Wind in Power-2016 European Statistics". https://windeurope.org/wp-content/uploads/files/about-wind/statistics/WindEuropeAnnual-Statistics-2016.pdf, 2016 (accessed 10.02.2017). 